\title{
Storage of halved strawberry fruits affects aroma, phytochemical content and gene expression.
}

\author{
R. Dhorajiwala, C. Roberts, S. Dimitrova, A. Baldwin, D. Davoli, R. Ludlow, S. Tu, S. Jones, N.
} Spadafora, C. Müller, H. Rogers

School of Biosciences, Sir Martin Evans Building, Museum Avenue, Cardiff, UK, CF10 3AX

\begin{abstract}
Strawberries are valued for their aroma and phytochemical content. However, they have a short shelf life and storage at low temperatures to prolong shelf life affects physiological and biochemical processes in the fruit. This impacts on their use in fresh cut ready-to-eat fruit salads. To assess changes in aroma and how these are related to phytochemical content and gene expression, Fragaria $x$ ananassa cv. Elsanta strawberries were halved and stored at either $4^{\circ} \mathrm{C}$ or $8{ }^{\circ} \mathrm{C}$ for a period of 12 days. Phytochemical content was relatively unaffected whereas volatile organic compound profiles were distinct at different time points of storage. Gene expression changed significantly with storage over a 5 day period: a total of 1135 gene targets changed in expression $(p<0.05 ; \log 2$ fold change $>1.5)$ with most changes between days 0 and 5 of storage. These included genes related to stress responses, and secondary metabolism. Real time PCR was used to verify expression profiles of two genes related to VOC classes represented in the aroma, showing changes in pattern of expression during storage.
\end{abstract}

Keywords: Fragaria $x$ ananassa Duch., transcriptomics, phytochemicals, volatile organic compounds

\section{INTRODUCTION}

The UK soft fruit market is worth approximately $£ 473.3$ million (2018) with strawberries representing over half of this value, worth $£ 283$ million (DEFRA, 2018). Cultivated strawberry, Fragaria $x$ ananassa, Duch. has been primarily bred for size and yield (Bertioli, 2019). This has resulted in the fruit being much larger than that of the wild species (Fragaria vesca), and with Fragaria x ananassa Duch. being octoploid rather than diploid (Edger et al., 2019). The distinctive aroma of strawberry fruit is made up of a wide range of volatile organic compounds (VOCs) including esters alcohols, aldehydes, furanones, sulphur compounds and terpenes (Forney et al., 2000; El Hadi et al., 2013). Esters are thought play a key role in the aroma profile with many of them associated with high-quality fruit (Shamaila et al., 1992; Pérez et al., 1996). Some of the biosynthetic pathways generating VOCs in strawberry fruit are known. For example, FaOMT, an 0-methyl transferase, catalyses the conversion of furaneol (2,5-dimethyl-4-hydroxy-3(2H)-furanone) to mesifurane (2,5-dimethyl-4-methoxy$3(2 \mathrm{H})$-furanone) (Wein et al., 2002). Furanones such as furaneol and mesifurane are important components of the strawberry aroma despite very low levels as both have low odour activity values (OAVs) with thresholds of 0.04 and $0.03 \mathrm{ppb}$ detection respectively (Loehndorf et al., 2000) and are essential for the characteristic strawberry aroma (Perez et al., 1996). Cinnamyl alcohol dehydrogenase (CAD) catalyses the last stage in the phenylpropanoid pathway and may be involved in the production of aroma compounds in strawberry receptacle cells (Mitchell and Jelenkovic, 1995). As well as being valued for their taste, strawberries also contain high levels of phytochemicals with potential health benefits including phenolics, vitamin C and folate (Tulipani et al., 2008; Giampieri et al., 2012). The key phenolics in strawberry fruit include flavonoids, hydrolysable tannins and phenolic acids. Amongst these are quercetin, and its derivatives such as quercetin-3-0-rutinoside (rutin), and the flavonoid catechin. 
Strawberry fruit has a short shelf life and is typically chilled during the supply chain from harvest to consumer (Mirzaee and Bishop, 2010). Chilling is used to slow down ripening and senescence postharvest (Pott et al. 2020). However, cold storage is associated with changes in fruit flavour related volatile organic compounds (Ayala-Zavala et al., 2004; Forney et al., 2000; Fu et al., 2017). Phytochemical content, including vitamin C levels of berries postharvest can also be affected by storage conditions (Kårlund et al. 2015). However, in strawberries phenolics seem to remain relatively constant in chilled storage of at least some cultivars (Pelayo et al., 2003).

Gene expression changes during strawberry fruit ripening (Li et al., 2015; Sánchez-Sevilla et al., 2017) as fruit softens and changes from green to red (Moya-León et al. 2019). Post-harvest gene expression is also affected by storage conditions (Zhang et al., 2019). Some of the genes relating to the biosynthesis of VOCs have also been studied. For example, variations in the strawberry FaOMT locus are thought to cause variation in mesifurane content (ZorrilaFontanesi et al. 2012).

\section{MATERIALS AND METHODS}

\section{Plant material}

Strawberry fruit (Fragaria x ananassa cv. Elsanta) were grown outdoors at Hendrewennol Fruit Garden, Bonvilston, Cowbridge near Cardiff and harvested. Strawberry fruit homogeneous in size, colour (at red ripe stage) and with no external damage were handpicked and processed within 3 hours. Fruit were washed with water, the calyx removed using a sharp knife, immersed in $1 \mathrm{~L}$ of 200 ppm sodium hypochlorite solution for $2 \mathrm{~min}$, air dried under sterile conditions, and chopped lengthways into halves using a sharp knife. The two halves were separated: one was stored at $4^{\circ} \mathrm{C}$ and the other at $8{ }^{\circ} \mathrm{C}$. Fruits were sampled destructively for VOCs before storage and then those stored at $8{ }^{\circ} \mathrm{C}$ were sampled at four further time points $(1,5,7$ and 12 days; Fig. 1). Controls were empty containers stored in the same way. For RNAseq and metabolite analysis halved fruit was stored at $8{ }^{\circ} \mathrm{C}$ and material collected at day 0, 1 and 5. Samples were rapidly sliced and snap frozen in liquid nitrogen then stored at $-80 \mathrm{C}$ until used. Three replicates of 12 halved fruit were used for each sampling point.

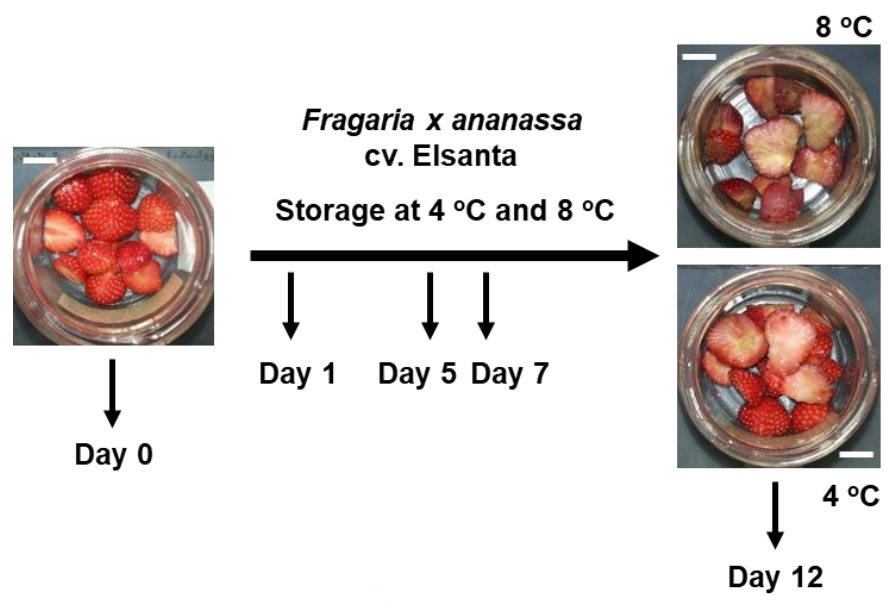

Figure 1. Experimental setup for strawberry sheif life experiment. Scale bar $=2 \mathrm{~cm}$

\section{VOC collection and analysis}

At each of the time points, VOCs were collected and processed essentially as described previously (Amaro et al., 2018) with minor modifications including that fruit samples were equilibrated for 2 hours and $400 \mathrm{~mL}$ of headspace was collected. Desorption on a TD100 system (Markes International) was followed by GC MS analysis (GC7890A, Agilent Technologies, Inc., BenchTOFdx,Markes International). Data were processed with AMDIS 
(NIST 2014) and ChemStation software (E.02.01.1177, Agilent Technologies, Inc.) as described previously (Amaro et al., 2018).

\section{RNA extraction and Transcriptomic analysis}

Fruit tissue was ground to a fine powder under liquid nitrogen and $150 \mathrm{mg}$ were used for extraction using a protocol adapted from Greco et al. (2014) based on CTAB extraction.

Random primed cDNA libraries were prepared using a TruSeq RNA Sample Prep kit (Illumina) and Illumina sequencing was performed using paired-end mode on an Illumina Next Seq 5000 Platform. Reads were assessed using FASTQ, and Trimmomatic was used to remove all adaptor sequences, as well as leading and trailing low quality or $\mathrm{N}$ bases. Over 21 M reads were obtained for each sample. The Fragaria vesca Whole Genome v2.0.a1 was used as the reference genome (sourced from Rosecae.org 2017) and the F. ananassa sequences were mapped using Star.

\section{Gene Ontology analysis}

Plant Transcriptional Regulatory Map (PlantRegMap, Jin et al., 2016) was used to analyse the significantly up-regulated or down-regulated genes from the RNA-seq data, both for the strawberry IDs already within the RNA-seq data set and Arabidopsis gene IDs which were assigned via a command line Blastx with the top hit being assigned. PlantRegMap analysis finds the significantly over-represented GO terms or parents of these terms from the input gene set. topGO and Fisher's exact tests are used by the analysis to obtain the GO terms that are significantly over-represented $(\mathrm{p}$-value $\leq 0.01)$ in the input gene list.

\section{Real Time PCR}

Following removal of genomic DNA, cDNA was synthesised from $2 \mu \mathrm{g}$ of total RNA using MMLV reverse transcriptase (Promega). Primers for qRT-PCR specific for the 0methyltransferase (OMT) gene was from Carbone et al. (2006), and for the elongation factor1 (EF1) gene from Amil-Ruiz et al. (2013), used as a control for transcript normalisation. The PCR consisted of $20 \mu \mathrm{L}$ of a mixture containing $10 \mu \mathrm{L}$ of SYBR Green (2x, PCR Biosystems), 0.4 $\mu \mathrm{L}$ of each sequence-specific primer, $6 \mu \mathrm{L}$ of sample cDNA (10 $\mu \mathrm{M}$ dilution). Each reaction was carried out in triplicate for each cDNA and gene. The PCR settings used were: $95^{\circ} \mathrm{C}$ for $5 \mathrm{~min}$, cycle $x 40$ of $95{ }^{\circ} \mathrm{C} 15 \mathrm{sec}, 60^{\circ} \mathrm{C} 30 \mathrm{sec}, 72{ }^{\circ} \mathrm{C} 30 \mathrm{sec}$, then $60^{\circ} \mathrm{C}$ for one min, $60^{\circ} \mathrm{C}$ for $30 \mathrm{sec}$, $98^{\circ} \mathrm{C}$ for $30 \mathrm{sec}$. Only Ct values with a range of 0.2 were used to normalise data and calculate relative expression.

\section{Analysis of phenolics}

Extraction and hydrolysis of phenolic compounds was adapted from (Tarola et al. 2013) using $0.25 \mathrm{~g}$ of frozen strawberry fruit. HPLC analyses were carried out on a ThermoScientific HPLC system (P4000 quaternary pump, AS300 autosampler and photodiode array detector (UV6000LP)) using a reversed phase C18 column with a $2 \%$ formic acid in $\mathrm{H}_{2} \mathrm{O}$ and $2 \%$ formic acid in $90 \%$ acetonitrile gradient(Tarola et al., 2013). Calibration standards were used for quercetin, catechin, and rutin (from Sigma Aldrich, $\geq 95 \%$ )

\section{Statistical analysis}

VOC profiles were analysed in $\mathrm{R}$ using Permutational Multivariate Analysis of Variance (PerMANOVA, adonis function in package vegan) and Canonical Analysis of Principal Ordinates (CAP, CAPdiscrim function in package BiodiversityR). Normality of datasets was tested using a Shapiro test, and equality of variance using a Fligner-Killeen test. Where datasets conformed to these tests ( $p>0.05$ ) a 2-way ANOVA was used followed by a Tukey's test. Where the data did not conform a Kurskal Wallis followed by a Dunn's test was used instead.

\section{RESULTS}

VOCs 
A total of 63 VOCs were detected in strawberries stored at $8{ }^{\circ} \mathrm{C}$ for up to 12 days (Fig. 2A). The greatest number were esters (acetate and non-acetate) representing over $70 \%$ of the total number, ketones and alcohols were the next most abundant VOC family with other VOC families representing a much smaller number of compounds in the profile. The whole VOC profiles were discriminated by day based on PerMANOVA $(p<0.01)$. A linear discrimination plot using the whole profile shows that there is clear discrimination between fresh cut fruit and fruit stored for 1 day (Fig. 2B). VOC profiles for fruit stored for 5 and 7 days were not

(A)

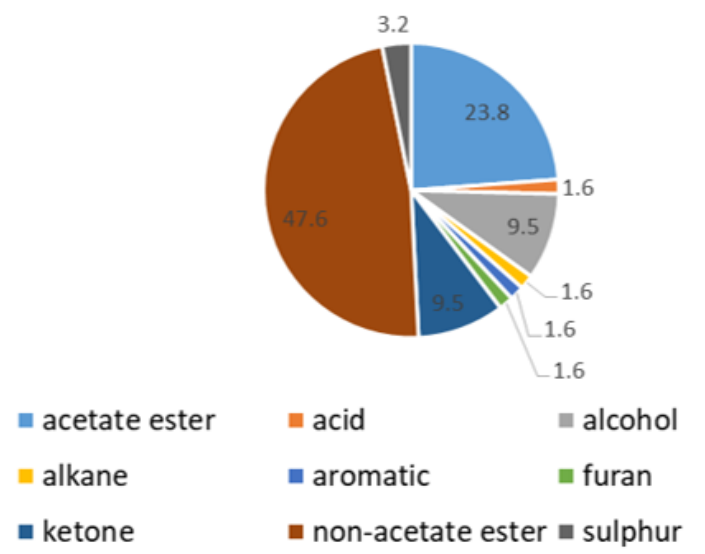

(B)

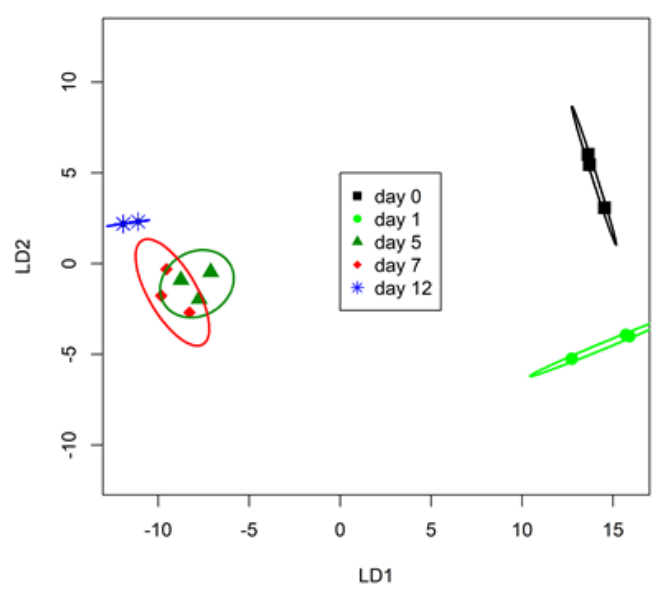

discriminated but VOCs on day 12 of storage were again discriminated from all other time points.

Figure 2- (A) \% of VOC families represented (B) Canonical Analysis of Principal coordinates of the VOC profile of halved strawberries stored at $8{ }^{\circ} \mathrm{C}$ for up to 12 days. Each ellipse represents the $95 \%$ confidence interval (SD). The plot uses linear discriminants LD1 and LD2 with a percentage of correct classification of $66.7 \%(n=3)$

\section{Phytochemicals}

Content of catechin, rutin and quercetin did not change significantly $(\mathrm{p}<0.05)$ across the first five days of storage of halved strawberries at $8^{\circ} \mathrm{C}$, although there was a slight mean increase in catechin and rutin. At 5 days relative content was more variable across replicate fruit (Fig. 3).

(A)

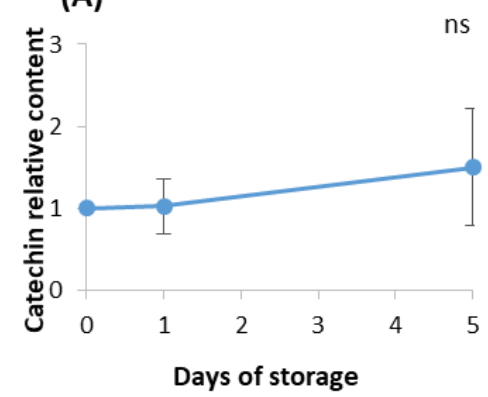

(B)

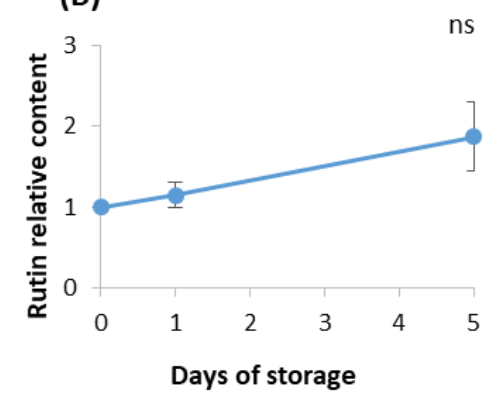

(C)

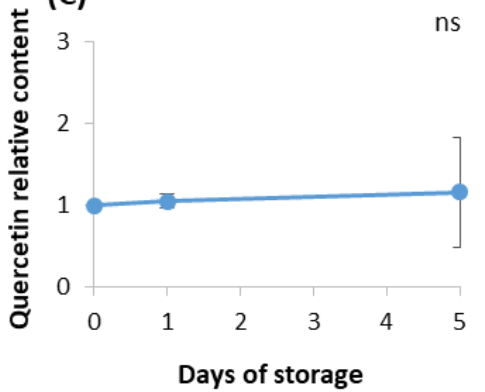

Figure 3 - Change in (A) catechin (B) rutin and (C) quercetin content in strawberry fruit that were halved and the stored at $8^{\circ} \mathrm{C}$ for 5 days as assessed by HPLC (mean \pm SE; $n=3$ biological replicates).

\section{Transcriptome}


A total of 1135 genes were identified as differentially expressed $\left(p<0.05\right.$; $\log _{2}$ fold change $>1.5$ ) amongst the strawberry transcripts expressed on day of cutting, and after 1 and 5 days of storage at $8{ }^{\circ} \mathrm{C}$. Most changes in gene expression were found in the comparison between day 5 and day 0 of storage ( 762 genes), lower numbers were changed between day 5 and day 1 (249 genes) and day 1 vs. day 0 (124 genes) (Fig. 4). There was most overlap in gene change between the day 5 vs day 0 and the day 5 vs day 1 than the other two comparisons.

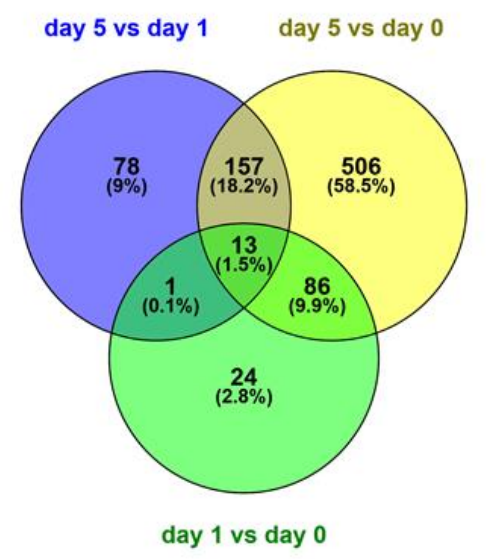

Figure 4- Changes in gene expression in pairwise comparisons amongst the three storage time points of strawberry fruit at $8{ }^{\circ} \mathrm{C}$ for 1 and 5 days (produced using Venny 2.0, http://bioinfogp.cnb.csic.es/tools/venny/).

Following functional annotation, 34-42 \% of differentially expressed genes related to response to stress, and 14-22 \% to secondary metabolism within GO terms relating to cellular processes. The comparison day 1 vs day 0 showed a higher $\%$ for both gene classes than day 5 vs. day 0 and day 5 vs. day 1 (Table 1 ).

Table 1 - Enriched differentially expressed genes (DEGs) as percentage total across three datasets from Fragaria $\mathrm{x}$ ananassa RNA-seq data relating to response to stress and secondary metabolism.

\begin{tabular}{llllr}
\hline $\begin{array}{l}\text { Day comparison and } \\
\text { regulation }\end{array}$ & Number of genes & & & \\
\hline & Response to stress & & secondary metabolism & \multicolumn{2}{c}{ TOTAL } \\
\hline d1 vs d0 & 42 & 22 & 124 \\
d5 vs d0 & 40 & 16 & 763 \\
d5 vs d1 & 34 & 14 & 249 \\
\hline
\end{tabular}

\section{Real Time PCR}

The effects of storage time and temperature on two genes related to the biosynthesis of VOCs, FaOMT and FaCAD was assessed (Fig. 5). FaOMT expression remained stable at both temperatures for the first day of storage but at day 5 there was significantly lower expression $(p<0.05)$ when the fruit were stored at $4{ }^{\circ} \mathrm{C}$ compared to $8{ }^{\circ} \mathrm{C}$. Expression was also higher in fruit stored at $8{ }^{\circ} \mathrm{C}$ after 7 days compared to 1 day, while at $4{ }^{\circ} \mathrm{C}$ the rise in expression was only significant between day 5 and day 12 . The pattern of FaCAD expression was different: expression at $4{ }^{\circ} \mathrm{C}$ peaked after 5 days. At $8{ }^{\circ} \mathrm{C}$ expression appeared to peak earlier at day 1 although there was variability across replicates, and the differences were not significant. 

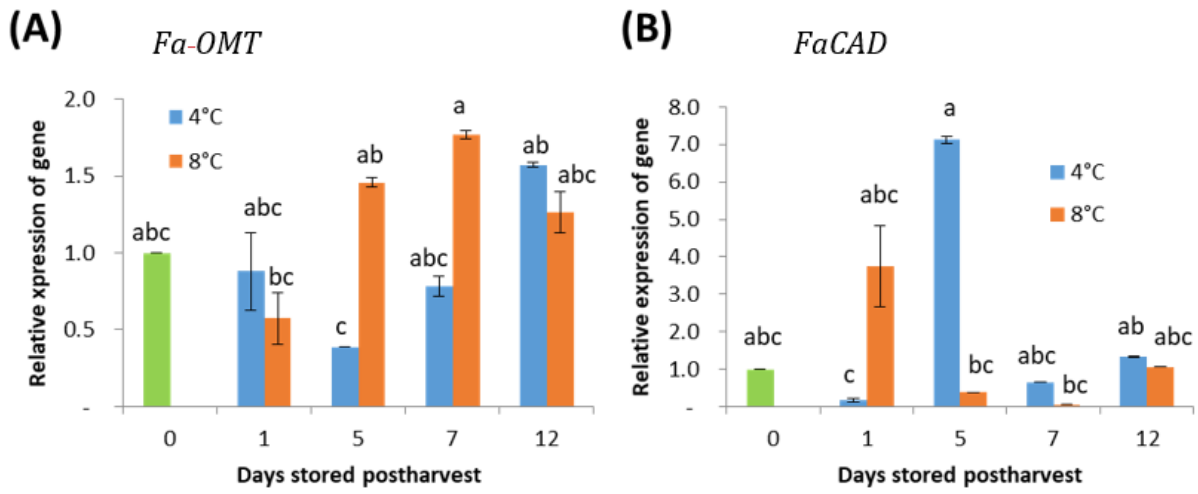

Figure 5- Comparison of change in relative expression of the strawberry (A) FaOMT and (B) FaCAD in fresh-cut strawberry over 12 days storage postharvest at 4 and $8{ }^{\circ} \mathrm{C}(\mathrm{n}=3$; + S.E. $)$. Different letters indicate significant differences $(\mathrm{p}<0.05)$.

\section{DISCUSSION}

The number of VOCs detected in this study is in line with other studies on individual varieties e.g. Van de Poel et al. (2014) who found 83 distinct VOCs in cv. Portola, although over 900 VOCs have been detected across strawberries in a wide range of different studies based on different detection methodologies (Ulrich et al., 2018). The VOC families and relatively high number of esters found here is also in agreement with previous studies (Forney et al., 2000; El Hadi et al. 2013; Ulrich et al., 2018). Changes in VOCs during storage have also been previously noted (e.g. Ayala-Zavala et al., 2004). Here we show that by using the whole volatilome we are able to clearly separate early stages of storage from later stages. By day 12 the strawberries had deteriorated well beyond their shelf life limit (Ayala-Zavala et al., 2004) and VOCs were distinct from the mid-storage time points. The overall profile might therefore be of use in assessing strawberry quality and predicting shelf-life.

In contrast to VOCs, no significant changes were noted in the phytochemicals assayed here over the first 5 days of storage. This contrasts with some reports on total phenolics (e.g. Ayala Zavala et al., 2004) which rose with storage at $5^{\circ} \mathrm{C}$, over a 12 day storage period, but is in line with other studies showing little change in phenolics during strawberry fruit shelf life (Pelayo et al., 2003; Shin et al., 2007). This may relate to cultivar differences or the specific storage temperature used.

The larger number of genes whose transcription changed in day 5 vs. day 1 compared to the genes that changed in expression between day 0 and day 1 probably reflects the longer storage period. However, the finding that a distinct set of genes is specific to each of these time intervals suggests that different processes are occurring early and later in shelf-life. During chilled storage, the fruit is subjected both to abiotic and biotic stress, as well as changing in ripeness, all of which affect their metabolism (Pott et al., 2020). It is therefore perhaps not surprising that a high proportion of the changed genes during post-harvest storage relate to stress responses. Interestingly a higher proportion of stress related genes change early in post-harvest compared to later. The high proportion of stress related genes whose expression changes in the first day of storage may relate to a wound response, known to change metabolites in strawberry fruit (Hamilton-Kemp et al., 2003) as well as an early response to chilling.

Numerous genes relating to secondary metabolites also change during chilled storage. This fits with studies showing changes in secondary metabolites during storage (Pott et al., 2020) and also changes in the expression of genes relating to secondary metabolites. For example expression of the strawberry gene encoding cinnamate: CoA ligase ( $F a C N L)$ fell rapidly in the first 2 days of storage (Fu et al., 2017), although other genes relating to aroma production such as FaOMT only changed in expression after 5 days of storage. In this study FaOMT expression also rose after about 5 days of storage at the higher storage temperature. The later expression when fruit were stored at the lower temperature could be due to the reduction in 
metabolism associated with the increased cold (Pott et al., 2020). A similar pattern was seen in the expression of FaCAD that rose earlier at the higher compared to the lower storage temperature. FaCAD is known to have maximum expression when strawberry fruit is mature (Blanco-Portales et al. 2002), so the increase here during storage may relate to the ripening which is slowed down at the lower storage temperature.

\section{Conclusion}

Overall we have shown that VOC profiles can be used to assess strawberry fruit shelf-life, and that there are significant changes in gene expression through shelf-life. Future work will focus on understanding the mechanisms underlying the changes in gene expression and VOCs during post-harvest storage, enabling better control of fruit quality.

\section{ACKNOWLEDGEMENTS}

$\mathrm{RD}, \mathrm{AB}$ and RL were funded by the BBSRC, DD was funded by the ERASMUS+ programme, CR, SD ST and SJ were funded by Cardiff University, NDS was funded by FP7/KBBE2011.2.4401/289719 - QUAFETY - "Comprehensive approach to enhance quality and safety of ready to eat fresh products".

\section{Literature cited}

Amaro, A. L., N. D. Spadafora, M. J. Pereira, R. Dhorajiwala, R. J.Herbert, C. T. Müller, H. J. Rogers, and M. Pintado. (2018). Multitraitanalysis of fresh-cut cantaloupe melon enables discrimination between storage times and temperatures and identifies potential markers for quality assessments. Food Chem. 241, 222-31.

Ayala-Zavala, J.F., Wang, S.Y., Wang, C.Y., Gonzalez-Aguila, G.A. (2004). Effect of storage temperatures on antioxidant capacity and aroma compounds in strawberry fruit. LWT 37, 687-95.

Bertioli, D.J. (2019). The origin and evolution of a favorite fruit. Nat. Genet. 51, 372-373.

Blanco-Portales, R., Medina-Escobar, N., Lopez-Raez, J.A., Gonzalez-Reyes, J.A., Villalba, J.M., Moyano, E., Caballero, J.L., Munoz-Blanco, J. (2002). Cloning, expression and immunolocalization pattern of a cinnamyl alcohol dehydrogenase gene from strawberry (Fragaria $\times$ ananassa cv. Chandler). J. Exp. Bot. 53:1723-34.

DEFRA, 2018. Horticultural Statistics. UK. https://www.gov.uk/government/collections/horticultural-statistics

Edger, P., Poorten, T., VanBuren, R., Hardigan, M., Colle, M., McKain, M., Smith, R., Teresi, S., Nelson, A., Wai, C et al. (2019). Origin and evolution of the octoploid strawberry genome. Nat. Genet. 51, 541-547.

El Hadi, M.A.M., Zhang, F., Wu, F., Zhou, C., Tao, J. (2013). Advances in fruit aroma volatile research. Molecules 18, 8200-229.

Forney, C.F., Kalt, W., Jordan, M.A. (2000). The composition of strawberry aroma is influenced by cultivar, maturity and storage. Hortic. Sci. 35, 1022-1026.

Fu, X. M., Cheng, S. H., Zhang, Y. Q., Du, B., Feng, C., Zhou, Y., Yang, Z. Y. (2017).Differential responses of four biosynthetic pathways of aroma compounds in postharvest strawberry (Fragaria ananassa Duch.) under interaction of light and temperature. Food Chem. 221, 356-364.

Giampieri, F., Tulipani, S., Alvarez-Suarez, J.M., Quiles, J.L., Mezzetti, B., Battino, M. (2012) The strawberry: composition, nutritional quality, and impact on human health. Nutrition 28, 9-1.

Greco, M., Saez, C.A., Brown, M.T., Bitonti, M.B. (2014). A Simple and Effective Method for High Quality CoExtraction of Genomic DNA and Total RNA from Low Biomass Ectocarpus siliculosus, the model Brown Alga. PLOS One 9:e96470

Hamilton-Kemp, T.R., Archbold, D.D., Collins, R.W. and Yu, K. (2003) Emission patterns of wound volatile compounds following injury ofripe strawberry fruit.J. Sci. Food Agric. 83: 283-288.

Jin, J., Tian, F., Yang, D.-C., Meng, Y.-Q., Kong, L., Luo, J., and Gao, G. (2016). PlantTFDB 4.0: toward a central hub for transcription factors and regulatory interactions in plants. Nucleic Acids Res. 45, 1040-1045. 
Kårlund, A., Moor, U., Sandell, M. Karjalainen, R. O. (2014) The impact of harvesting, storage and processing factors on health-promoting phytochemicals in berries and fruits. Processes 2, 596-624.

Li, D., Li, L., Luo, Z., Mou, W., Mao, L., Ying, T. (2015) Comparative transcriptome analysis reveals the influence of abscisic acid on the metabolism of pigments, ascorbic acid and folic acid during strawberry fruit ripening. PLoS ONE 10, e0130037.

Loehndorf, J.R., Sims, C.A., Chandler, C.K., Rouseff, R. (2000). Sensory properties and furanone content of strawberry clones grown in Florida. Proceedings of the Florida State Horticultural Society 113, 272-6.

Mirzaee, M. and Bishop, C. (2010). The packaging implications of the 'last mile of the strawberry supply chain'. Acta Hortic. 877, 967-972.

Mitchell, W.C., Jelenkovic, G. (1995) Characterizing NAD- and NADP-dependent alcohol dehydrogenase enzymes of strawberries. J. Am. Soc. Hortic. 120, 798-801.

Moya-León, M.A., Mattus-Araya, E. and Herrera, R. (2019). Molecular Events Occurring During Softening of Strawberry Fruit. Front. Plant Sci. 10:615.

Pelayo, C., Ebeler, S.E., Kader, A.A. (2003) Postharvest life and flavor quality of three strawberry cultivars kept at $5{ }^{\circ} \mathrm{C}$ in air or air $+20 \mathrm{kPa}$ CO2. Postharvest Biol. Technol. 27, 171-183.

Perez, A.G., Sanz, C., Olias, R., Rios, J.J., Olias, J.M. (1996). Evolution of strawberry alcohol acyltransferase activity during fruit development and storage. J. Agric. Food Chem. 44:3286-90.

Pott, D.M., Vallarino, J.G. and Osorio, S. (2020). Metabolite changes during postharvest storage: Effects on fruit quality traits. Metabolites 10, 187.

Sánchez-Sevilla, J.F., Vallarino, J.G., Osorio, S., Bombarely, A., Posé, D., Merchante, C., Botella, M.A., Amaya, I., Valpuesta, V. (2017) Gene expression atlas of fruit ripening and transcriptome assembly from RNA-seq data in octoploid strawberry (Fragaria x ananassa). Scientific Reports 7, 13737.

Shamaila M, Baumann TE, Eaton GW, Powrie WD, and Skura BJ (1992). Quality attributes of strawberry cultivars grown in British Columbia. J. Food Sci.. 57:696-699

Shin Y., Liu R.H., Nock J.F., Holliday D., Watkins C.B (2007) Temperature and relative humidity effects on quality, total ascorbic acid, phenolics and flavonoid concentrations, and antioxidant activity of strawberry Postharvest Biol. Technol. 45 pp. 349-357

Tarola A., Van de Velde F., Salvagni L., Preti R. (2013) Determination of phenolic compounds in strawberries (Fragaria ananassa Duch) by high performance liquid chromatography with diode array detection. Food Analytical Methods 6: 227-237

Tulipani S, Mezzetti B, Capocasa F, Bompadre S, Beekwilder J,Ric de Vos CH, et al. (2008) Antioxidants, phenolic compounds, and nutri-tional quality of different strawberry genotypes. J Agric Food Chem, 56:696-704.

Ulrich, D., Kecke, S., and Olbrich, K. (2018). What do we know about the chemistry of strawberry aroma? J. Agric. Food Chem. 66, 3291-3301

Van de Poel, B., Vandendriessche, T., Hertog, M. L. A. T. M., Nicolai, B. M., \& Geeraerd, A. (2014). Detachedripening of non-climacteric strawberry impairs aroma profile and fruit quality. Postharvest Biol. Technol. 95, 70-80.

Wein M, Lavid N, Lunkenbein S, Lewinsohn E, Schwab W, Kaldenhoff R (2002) Isolation, cloning and expression of a multifunctional 0-methyltransferase capable of forming 2,5-dimethyl-4-methoxy-3(2H)-furanone, one of the key aroma compounds in strawberry fruits. Plant J 31: 755-765

Zhang L, Wang L, Zeng X, Chen R, Yang S and Pan S, (2019) Comparative transcriptome analysis reveals fruit discoloration mechanisms in postharvest strawberries in response to high ambient temperature. Food Chem: X 2:100025.

Zorrila-Fontanesi, Y., Rambla, J.L., Cabeza, A. et al. (2012). Genetic analysis of strawberry fruit aroma and identification of O-methyltransferase FaOMT as the locus controlling natural variation in mesifurane content. Plant Physiol. 159:851-70. 